\title{
PENGARUH NON PERFORMING FINANCING, FINANCING TO DEPOSIT RATIO DAN INFLASI TERHADAP EFISIENSIMENGGUNAKAN RASIO BOPO PADA BANK SYARIAH DI INDONESIA PERIODE 2010-201511
}

\author{
Shinta Puspitasari Hidayat \\ Mahasiswa Program Studi Ekonomi Islam-Fakultas Ekonomi dan Bisnis-Universitas Airlangga \\ Email: shinta.puspitasari-11@feb.unair.ac.id
}

\author{
Ari Prasetyo \\ Departemen Ekonomi Syariah- Fakultas Ekonomi dan Bisnis-Universitas Airlangga \\ Email: ari.prasetyo@feb.unair.ac.id
}

\begin{abstract}
:
This research attempt to analyze the effect of variableNon Performing Financing (NPF), Financing to Deposit Ratio (FDR) and inflation towards BOPO in syariah public bank and syariah business unit in Indonesia. This research uses qualitative approach. The data used in here is monthly data during 2010-2015. Typedof data used are the secondary data from official website Indonesian Bank. The analysis method used is multiple linear regression analysis method with significance level of 0,05. The result shows that non performing financing partially affects significantly towards BOPO ratio. Financing to deposit ratio and inflation don't affect significantly towards BOPO ratio. However, non performing financing, financing to deposit ratio and inflation simultaneously affect significantly towards the ratio of BOPO.
\end{abstract}

Keywords: BOPO, Non Performing Financing, Financing to Deposit Ratio, Inflation.

\section{PENDAHULUAN}

\section{Latar Belakang}

Pertumbuhan Bank Syariah

dilndonesia sangat pesat hingga sekarang ini, mulai dari Unit Usaha suatu bank hingga Bank Umum Syariah yang ada di Indonesia jumlahnya makin bertambah tiap tahunnya. Jumlah kantornya yang tersebar mulai mencakup daerah yang jauh dari ibu kota dan kota besar, sehingga masyarakat desa sekarang ini dapat menikmati keuntungan yang ditawarkan pada bank syariah. Dahulu masyarakat khawatir menitipkan dananya kepada bank karena adanya unsur riba, namun sekarang tidak perlu khawatir karena bank syariah tidak menganut sistem bunga yang diterapkan oleh bank konvensional.

Baik di Bank Syariah maupun Bank Konvensional efisiensi pada bank sangat diperhatikan, dan salah satu rasio efisiensi yaitu BOPO. Pada penelitian ini Non Performing Financing, Finacing to Deposit Ratio dan Inflasi di duga berpengaruh terhadap BOPO di perbankan syariah. Selama periode penelitian BOPO dan NPF mengalami kenaikan bersamaan pada tahun 2015 sebesar $86,87 \%$ pada BOPO dan 4,73\% pada NPF. Menurut Direktur Utama BNI Syariah Dinno Indiano,

"Kenaikan BOPO ini juga disebabkan oleh pencadagan yang terbentuk akibat pembiayaan bermasalah (NPF), beberapa bank syariah membuat cadangan yang lebih karena ditengah kondisi ekonomi seperti sekarang ini NPF pasti meningkat".

Hal tersebut karena rasio NPF yang tinggi, sehingga sebelum menurunkan rasio BOPO pemerintah dapat melakukan menghilangkan Cost of Fund atau dana

1) Jurnal ini merupakan bagian dari skripsi dari Shinta Puspitasari Hidayat, NIM : 041114121 , yang diuji pada 24 juni 2016 
Hidayat, et al/Jurnal Ekonomi Syariah Teori dan Terapan Vol. 4 No. 3 Maret 2017: 187-202; PENGARUH NON PERFORMING FINANCING, FINANCING TO DEPOSIT RATIO DAN INFLASI TERHADAP EFISIENSIMENGGUNAKAN RASIO BOPO PADA BANK SYARIAH DI INDONESIA PERIODE 2010-2015

mahal, yaitu dengan cara dana APBN agar disimpan di bank syariah sehingga bisa meningkatkan DPK bank syariah. Selain BOPO dan NPF, FDR dan Inflasi juga mengalami kenaikan pada tahun 2012 hingga 2013 untuk FDR dan pada tahun 2013 hingga 2014 untuk Inflasi.

Menurut penelitian sebelumnya yang dilakukan oleh Setyawati dan Suartana(2014) dengan judul Pengaruh pertumbuhan Aktiva Produktif, Dana Pihak Ketiga, Tingkat Kredit Bermasalah dan Ukuran LPD terhadap Kinerja Operasional membuktikan hubungan dari Financing Deposit Ratio dan Non Performing Financing menunjukkan hubungan yang positif pada rasio BOPO. Pada penelitian yang dilakukan oleh Santoso (2011) dengan judul Pengaruh Non Performing Loanterhadap Rasio BOPO (Studi kasus pada Bank yang Listing di Bursa Efek Indonesia) membuktikan bahwa hubungan Non Performing Loan menunjukkan adanya hubungan sebesar $11,76 \%$ pada rasio BOPO. Meskipun adanya hubungan yang kecil, namun tetap saja Non Performing Loan memiliki hubungan positif terhadap rasio BOPO. Dan penelitian Fauziah (2012) menunjukkan bahwa tingkat Profitabilitas pada bank dapat dipengaruhi oleh tingkat inflasi. Pada rasio Profitabilitas bank di penelitian tersebut di proksikan terhadap $R O A, R O E$, dan BOPO.Adapun perbedaan penelitian terdahulu dengan penelitian ini adalah pada variabel independen yang berbeda dan tahun periode penelitiannya.

Adapun rumusan masalah pada penelitian ini adalah sebagai berikut:
1. Apakah variabel NPF, FDR dan Inflasi berpengaruh secara parsial pada BOPO Bank Umum Syariah dan Unit Usaha Syariah?

2. Apakah variabel NPF, FDR dan Inflasi berpengaruh secara simultan pada BOPO Bank Umum Syariah dan Unit Usaha Syariah?

Tujuan dari Penelitian penelitian ini adalah Untuk mengetahui apakah variabel NPF, FDR dan Inflasi berpengaruh secara parsial pada BOPO Bank Umum Syariah dan Unit Usaha Syariah, dan Untuk mempengaruhi apakah variabel NPF, FDR dan Inflasi berpengaruh secara simultan pada BOPO Bank Umum Syariah dan Unit Usaha Syariah.

\section{LANDASAN PUSTAKA}

Menurut Sudarsono (2004:27), bank syariah adalah lembaga kevangan yang usaha pokoknya memberikan kredit dan jasa-jasa lain dalam lalu lintas pembayaran serta peredaran vang yang beroperasi disesuaikan dengan prinsip syariah. Sistem perekonomian umat Islam memiliki konsep sendirilembaga keuangan atau bank yang sesuai syariat islam, bank dalam islam memiliki prinsip operasional yang berbeda dengan prinsip operasional bank konvensional. Landasan yang digunakan pada bank syariah berbeda dengan bank konvensional pada umumnya. Bank konvensional beroperasi berdasarkan bunga, sedangkan bank syariah beroperasi berdasarkan sistem bagi hasil.Sistem bagi hasil ini pembagian keuntungan yang diperoleh dibagi sesuai dengan kesepakatan antara bank dan nasabah, 
Hidayat, et al/Jurnal Ekonomi Syariah Teori dan Terapan Vol. 4 No. 3 Maret 2017: 187-202; PENGARUH NON PERFORMING FINANCING, FINANCING TO DEPOSIT RATIO DAN INFLASI TERHADAP EFISIENSIMENGGUNAKAN RASIO BOPO PADA BANK SYARIAH DI INDONESIA PERIODE 2010-2015

sehingga bank syariah menganut sistem kemitraan, yang dimana nasabah pada bank syariah dianggap sebagai mitra bisnis oleh pihak bank.

Perbankan Syariah yang lebih dikenal sebagai bank bebas bunga ini sangat diminati banyak kalangan baik muslim maupun non muslim. Penyebarannya sangat luas, tidak hanya di negara para kaum muslim saja namun banyak juga tersebar di negara non muslim.

"Penyebaran dari perekonomian islam ini tidak hanya dalam bentuk perbankan saja namun juga dalam bentuk investment companies, holding companies dan juga berupa perusahaan-perusahaan asuransi yang tersebar hingga di 45 negara di dunia" (Muhammad, 2005:74).

BOPO yang sering disebut rasioefisiensi ini digunakan untuk mengukur kemampuan manajemen bank dalam mengendalikan biaya operasional terhadap pendapatan operasional. Dendawijaya, (2009:121) menyatakan bahwa semakin kecil rasio ini semakin efisiensi biaya operasional yang dikeluarkan bank yang bersangkutan sehingga kemungkinan suatu bank dalam kondisi bermasalah semakin kecil dan profitabilitas meningkat. Menurut Karyadi dalam Arifin $(2009 ; 2)$ rasio ideal BOPO berkisar 70\%-80\%, sehingga apabila prosentase BOPO melebihi rasio idealnya maka bank tersebut dikatakan inefisiensi. inefisiensi bank tersebut dikarenakan karena Biaya Operasional yang sangat tinggi dan Pendapatan Operasional yang tidak cukup tinggi. BOPO dapat dihitung dengan rumus:

$$
B O P O=\frac{\text { biaya operasional }}{\text { pendapatan operasional }} \times 100 \%
$$

Manfaat masyarakat mengetahui rasio BOPO adalah masyarakat akan tahu seberapa efisien bank tersebut dalam mengendalikan biaya operasionalnya. Semakin efisien bank, maka bank tersebut bisa dikatan sehat dan masyarakat akan lebih percaya dengan bank tersebut.

Non Performing Financing (NPF) adalah presentase pembiayaan yang bermasalah pada suatu bank.NPF pada perbankan konvensional biasanya dikenal dengan Non Performing Loan (NPL).Berdasarkanketentuan Bank Indonesia saat ini NPF maksimal adalah sebesar 5\%. Kriteria penilaian tingkat kesehatan rasio NPF.Bank syariah NPF dihitung berdasarkan perbandingan antara jumlah pembiayaan yang bermasalah dibandingkan dengan total pembiayaan, sama seperti rumus pada rumus NPL pada bank konvensional.

$$
N P F=\frac{\text { Pembiayaanbermasalah }}{\text { totalPembiayaan }} \times 100 \%
$$

NPF sangat berpengaruh terhadap pengendalian biaya dan sekaligus juga berpengaruh terhadap kebijakan pembiayaan yang akan dilakukan bank itu sendiri. Non Performing Finance (NPF) dapat mendatangkan dampak yang tidak menguntungkan terlebih lagi kalau NPF dalam jumlah besar. Peningkatan jumlah NPF akan meningkatkan jumlah Penyisihan Penghapusan Aset Produktif (PPAP) yang perlu dibentuk oleh pihak bank. Hal 
Hidayat, et al/Jurnal Ekonomi Syariah Teori dan Terapan Vol. 4 No. 3 Maret 2017: 187-202; PENGARUH NON PERFORMING FINANCING, FINANCING TO DEPOSIT RATIO DAN INFLASI TERHADAP EFISIENSIMENGGUNAKAN RASIO BOPO PADA BANK SYARIAH DI INDONESIA PERIODE 2010-2015

tersebut dapat terjadi karena jika NPF tinggi maka profitabilitas bank tersebut menurun, sehingga bank perlu meningkatkan jumlah PPAP agar bank tersebut masih dapat beroperasi. Jika hal itu berlangsung terus maka akan mengurangi modal bank, sehingga kemampuan pengelolaan pembiayaan sangat diperlukan oleh bank syariah.

Finance to Deposit Ratio (FDR) merupakan rasio pembiayaan terhadap dana pihak ketiga yang diterima oleh bank.FDR sebagai indikator dari pembiayaan merupakan jumlah atau posisi dari pembiayaan yang diberikan oleh bank.Menghitung tingkat FDR bertujuan untuk mengetahui dan sebagai acuan untuk evaluasi seberapa jauh suatu bank dalam kondisi sehat dalam pelaksanaan operasional bank. FDR digunakan bank sebagai suatu indikator untuk mengetahui tingkat kerawanan suatu bank.

Tingkat FDR suatu bank pada posisi rendah maka likuiditas dari bank tersebut lancar, namun jika tinggi maka likuiditas bank tersebut dalam keadaan tidak baik. Dendawijaya (2001:118), menyatakan bahwa semakin tinggi rasio tersebut memberikan indikasi semakin rendahnya kemampuan likuiditas bank yang bersangkutan. Hal ini disebabkan karena jumlah dana yang diperlukan untuk membiayai kredit menjadi semakin besar. Likuiditas pada bank menunjukan adanya ketersediaan dana dan sumber dana bank pada saat ini dan masa yang akan datang. Pengaturan likuiditas bank dimaksudkan agar bank setiap saat dapat memenuhi kewajiban - kewajiiban yang harus segera dibayar.

Bank syariah untuk mengakui pendapatan dengan mempertimbangkan rasio antara pembiayaan yang diberikan dan DPK, serta pendapatan yang dihasilkan dari perpaduan dua faktor tersebut (Muhammad, 2002) dalam (Hartono, 2007:5). Financing to Deposit Ratio atau Loan to Deposit Ratio (LDR) dalam bank konvensional dapat dihitung dengan rumus:

$$
F D R=\frac{\text { jumlahkredityangdiberikan }}{\text { danapihakketiga }} \times 100 \%
$$

Rasio FDR yang ditentukan oleh Bank Indonesia minimal78-92\% yang bisa dikatakan bahwa bank tersebut tidak dalam kondisi bermasalah. Manfaat masyarakat mengetahui rasio FDR adalah masyarakat akan mengetahui jumlah kredit yang diberikan kepada masyarakat. Apabila rasio FDR ini tinggi maka prediksi kondisi bermasalah pada bank akan besar karena kemungkinan terjadi kredit macet dan merugikan bank maupun masyarakat.

$$
\text { Menurut Karim (2007:135), inflasi }
$$
adalah tingkat harga yang mengalami kenaikan secara umum dari barang atau komoditas dan jasa selama suatu periode waktu tertentu. Inflasi merupakan salah satu fenomena moneter, karena nilai unit penghitungan moneter mengalami penurunan terhadap suatu komoditas. Definisi inflasi menurut Boediono (1985:155), adalah kecenderungan dari naiknya harga-harga secara umum dan terus menerus, namun jika kenaikan harga hanya 
Hidayat, et al/Jurnal Ekonomi Syariah Teori dan Terapan Vol. 4 No. 3 Maret 2017: 187-202; PENGARUH NON PERFORMING FINANCING, FINANCING TO DEPOSIT RATIO DAN INFLASI TERHADAP EFISIENSIMENGGUNAKAN RASIO BOPO PADA BANK SYARIAH DI INDONESIA PERIODE 2010-2015

berkisar dari satu atau dua barang saja tidak dapat disebut inflasi, namun bila kenaikan tersebut meluas kepada (atau mengakibatkan kenaikan) sebagian besar dari harga barang-barang yang lain. Berdasarkan kedua denifinisi inflasi menurut para ahli tersebut, inflasi dapat diartikan sebagai kenaikan harga pada banyak barang dan jasa yang terjadi secara terus menerus di suatu tempat dalam periode tertentu.

Menurut Boediono (1985:156-158) penggolongan inflasi dapat didasarkan atas tingkat keparahan inflasi, penggolongan inflasi berdasarkan tingkat keparahannya adalah sebagai berikut:

1. Inflasi ringan (dibawah $10 \%$ setahun)

2. Inflasi sedang (antara $10-30 \%$ setahun)

3. Inflasi berat (antara 30-100\% setahun)

4. Hiperinflasi (di atas $100 \%$ setahun) adapun formula untuk menghitung tingkat inflasi adalah sebagai berikut:

$$
\begin{aligned}
& \text { Inflasi }=\frac{\mathrm{IHK}_{1}-\mathrm{IHK}_{0}}{I H K_{0}} \times 100 \% \\
& \text { Hubungan Antar Variabel pada }
\end{aligned}
$$
penelitian ini pertama adalah NPFberpengaruh terhadap BOPO.Salah satu ukuran efisiensi bank adalah rasio Non Performing Financing. Pengertian dari Non Performing Financing sendiri adalah presentase pembiayaan yang bermasalah pada suatu bank. Tingkat NPF meningkat dikarenakan banyaknya pembiayaan yang bermasalah di bank, adapun permasalahan dari pembiayaan biasanya dikarenakan adanya gagal bayar oleh nasabah. Jika nasabah tidak dapat membayar cicilan pembiayan yang di ambilnya maka pedapatan dari bank dan menimbulkan biaya operasional berupa biaya penagihan kepada nasabah tersebut. BOPO berkaitan erat dengan kegiatan operasional bank, yaitu penghimpunan dana dan penggunaan dana oleh bank tersebut. Dengan tingginya pembiayaan bermasalah bank akan susah dalam mendapatan dana utuk operasionalnya, dan bank membutuhkan biaya operasional juga untuk penagihan kepada nasabah. Jika pendapatan bank lebih kecil dari biaya operasionalnya maka dapat menekan rasio BOPO.

Hubungan antar variabel berikutnya adalah FDR berpengaruh terhadap BOPO,Faktor lain yang diduga dapat mempengaruhi BOPO yaitu FDR. FDR adalah singkatan dari Finance to Deposit Ratio yaitu rasio pembiayaan terhadap dana pihak ketiga yang diterima oleh bank. Tingginya rasio FDR memiliki dampak yang sama dengan tingginya rasio NPF terhadap BOPO. Semakin tinggi rasio FDR maka juga menyebabkan berkurangnya pendapatan bank dan meningkatkan biaya operasionalnya juga. Rasio FDR dapat meningkat jika jumlah dana pihak ketiga lebih kecil dari jumlah pembiayaan yang diberikan oleh bank. Jika jumlah pembiayaannya terlalu bayak dan tidak seimbang dengan jumah DPK sehingga akan meningkatkan biaya operasional bank, dengan tetapnyapendapatan bank dan lebih besar biaya operasionalnya dari pada pendapatannya, sehingga rasio BOPO akan tinggi. 
Hidayat, et al/Jurnal Ekonomi Syariah Teori dan Terapan Vol. 4 No. 3 Maret 2017: 187-202; PENGARUH NON PERFORMING FINANCING, FINANCING TO DEPOSIT RATIO DAN INFLASI TERHADAP EFISIENSIMENGGUNAKAN RASIO BOPO PADA BANK SYARIAH DI INDONESIA PERIODE 2010-2015

Faktor terakhir yang diduga mempengaruhi rasio BOPO yaitu tingkat inflasi. Inflasi adalah tingkat harga yang mengalami kenaikan secara umum dari barang atau komoditas dan jasa selama suatu periode waktu tertentu. Buruknya perekonomian dapat berdampak pada biaya operasional bank yang semakin meningkat. Selain dari meningkatnya biaya operasional bank juga dapat mempengaruhi pemasukan kepada bank, sehingga dapat mempengaruhi tingkat rasio BOPO. Meningkatnya biaya operasional dan pendaapatan operasional yang tetap dapat membuat rasio BOPO mengalami kenaikan.

Model Analisis

Model analisa yang digunakan dalam penelitian ini disusun dengan persamaan sebagai berikut:

$$
Y=\alpha+\beta_{1} X_{1}+\beta_{2} X_{2}+\beta_{3} X_{3}+e
$$

dimana :

$Y_{i}=$ Biaya Operasional terhadap

Pendapatan Operasional

$\alpha=$ Konstanta dari persamaan regresi

$\beta_{1}=$ Koefisien regresi dari variabel Non Performing Financing

$\mathrm{X}_{1}=$ Variabel Non Performing Financing

$\beta_{2}=$ Koefisien regresi dari variabel Financing to Deposit Ratio

$\mathrm{X}_{2}=$ Variabel Financing to Deposit Ratio

$\beta_{3}=$ Koefisien regresi dari variabel Inflasi

$X_{3}=$ Variabel Inflasi

e $=$ Residual atau kesalahan prediksi

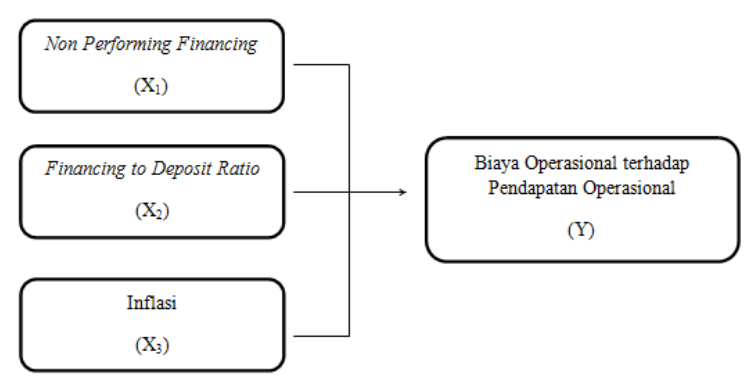

Gambar 1.

Kerangka Model Analisis

\section{METODOLOGI PENELITIAN}

\section{A. Pendekatan Penelitian}

Pendekatan yang digunakan dalam penelitian ini adalah pendekatan penelitian kuantitatif. Pendekatan ini menitikberatkan pada pengujian hipotesis.

\section{B. Identifikasi Variabel}

Ada dua jenis variabel yang digunakan yaituvariabel bebas yang meliputi NPF, FDR dan Inflasiserta variabel terikat yaituBOPO.

\section{Definisi Operasional Variabel}

Definisi Operasional Variabel dalam penelitian ini adalah:

1. Biaya Operasional terhadap Pendapatan Operasional (BOPO)

BOPO yang sering disebut rasio efisiensi ini merupakan ukuran kemampuan manajemen bank dalam mengendalikan biaya operasional terhadap pendapatan operasional. meningkat, sehingga rasio bank dalam kondisi bermasalah semakin kecil. Pada penelitian ini variabel BOPO merupakan variabel dependen. Data BOPO bersumber dari Statistik Perbankan Syariah (Rasio Keuangan pada Bank Umum Syariah) periode 
Hidayat, et al/Jurnal Ekonomi Syariah Teori dan Terapan Vol. 4 No. 3 Maret 2017: 187-202; PENGARUH NON PERFORMING FINANCING, FINANCING TO DEPOSIT RATIO DAN INFLASI TERHADAP EFISIENSIMENGGUNAKAN RASIO BOPO PADA BANK SYARIAH DI INDONESIA PERIODE 2010-2015

Januari 2010-Juni 2015 yang berjumlah 66 data.

2. Non Performing Financing (NPF)

Pembiayaan bermasalah atau Non Performing Financing (NPF) adalah presentase pembiayaan yang bermasalah pada suatu bank.Penelitian ini variabel NPF merupakan variabel independen. Data NPF bersumber dari Statistik Perbankan Syariah (Rasio Kevangan pada Bank Umum Syariah) periode Januari 2010Juni 2015 yang berjumlah 66 data.

3. Inflasi

Inflasi adalah tingkat harga yang mengalami kenaikan secara umum dari barang atau komoditas dan jasa selama suatu periode waktu tertentu . Pada penelitian ini variabel ini merupakan variabel independen. Data inflasibersumber dari web Bank Indonesia periode Januari 2010-Juni 2015 yang berjumlah 66 data.

4. Financing on Deposit Rasio (FDR)

Rasio FDR ini digunakan sebagai pengukur likuiditas suatu bank. Pada penelitian ini variabel FDR merupakan variabel independen. Data FDR bersumber dari Statistik Perbankan Syariah (Rasio Keuangan pada Bank Umum Syariah) periode Januari 2010Juni 2015 yang berjumlah 66 data.

\section{Populasi dan Sampel}

Populasi yang digunakan dalam penelitian ini adalah industri perbankan syariah dalam bentuk Unit Usaha Syariah dan Bank Umum Syariah yag ada di Indonesia. Dimana populasi dalam penelitian ini diambil dari data bulananpada Statistik Perbankan Syariah mulaiperiode 2010-juni2015.Data yang dianalisis dalam penelitian ini adalah data sekunder dengan periode bulanan dari bulan januari 2010 hingga juni 2015 ,sehingga populasi dalam penelitian ini berjumlah 66 data.

\section{E. Teknik Analisis}

Teknik analisis yang digunakan adalah regresi linier berganda.Penggunaan teknik analisis ini untuk mengetahui pengaruh variabel bebas terhadap variabel terikat secara simultan dan parsial. Berikut adalah teknikanalisis yang dilakukan:

1. Statistik Deskriptifdigunakan untuk mendapatkan gambaran umum sampel penelitian meliputi mean, nilai maksimum, nilai minimum, varian $\left(\sigma^{2}\right)$, dan standar deviasi $(\sigma)$ dari setiap variabel dalam model.

2. Uji Asumsi Klasik

a. Uji Normalitas, untuk mengetahui apakah data yang digunakan terdistribusi normal atau tidak. Melalui grafik P-P Plot histogram.

b. Uji Multikolinearitas, untuk mengetahui apakah terdapat korelasi antar variabel bebas. Dilakukan dengan melihat nilai VIF dan Tolerance

c. Uji Autokorelasi, Pengujian ini bertujuan untuk menguji apakah dalam sebuah regresi-regresi linear terdapat kolerasi antara kesalahan penggangu pada periode $t$ dan kesalahan penggangu pada periode t-1 atau periode sebelumnya. 
Hidayat, et al/Jurnal Ekonomi Syariah Teori dan Terapan Vol. 4 No. 3 Maret 2017: 187-202; PENGARUH NON PERFORMING FINANCING, FINANCING TO DEPOSIT RATIO DAN INFLASI TERHADAP EFISIENSIMENGGUNAKAN RASIO BOPO PADA BANK SYARIAH DI INDONESIA PERIODE 2010-2015

Mengujian ini menggunakan uji Durbin Watson (DW) test.

d. Uji Heteroskedastisitas, bertujuan untuk menguji apakah dalam model regresi tersebut terdapat ketidak-samaan varian dari residual satu pengamatan ke pengamatan lainnya. Dilihat melalui grafik Scatter Plot.

3. Kriteria Statistik Model

a. Koefisien Determinasi $\left(R^{2}\right)$ dan Adjusted $R^{2}$ digunakan untuk mengukur seberapa baik garis regresi sesuai dengan data aktualnya (goodness of fit). Koefisien determinasi ini mengukur prosentase total variasi variabel $Y$ yang dijelaskan oleh variabel independen didalam regresi.

b. Regresi linier Berganda, untuk melihat hubungansecara simultan antaravariabel bebas dengan variabel terikat, serta menentukan sifat hubungan tersebut.

c. Uji T digunakan untuk membuktikan apakah variabel independen secara individu mempengaruhi variabel dependen (Widardjono, 2010:25).

d. Uji $F$ digunakan untuk mengevaluasi pengaruh semua variabel independen terhadap variabel dependen (Widardjono, 2010:22). Maksudnya apakah semua variabel independensecara bersama-sama (simultan) berpengaruh terhadap variabel dependen.

\section{HASIL PENELITIAN DAN PEMBAHASAN}

\section{A.Uji Asumsi Klasik}

\section{Uji Normalitas}

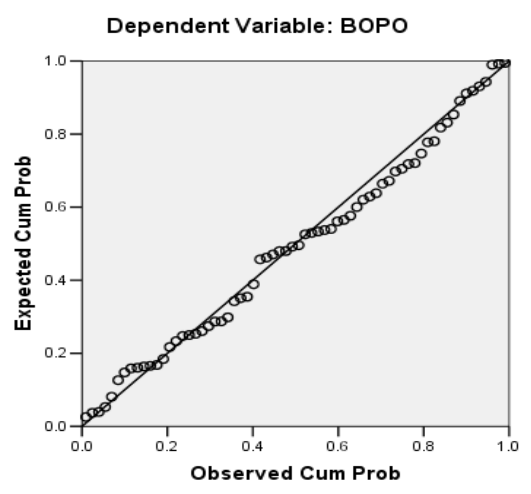

Gambar 2.

Grafik Normal P-P Plot

Berdasarkangrafik Normal P-P Plot of Regression Standardized Residual diatas, diketahui bahwa titik-titik terkumpul di sekitar garis lurus, sehingga disimpulkan residual model regresi mengikuti distribusi normal. Hasil di atas diperkuat dengan hasil uji kolmogorov smirnov. Jika nilai signifikansi uji kolmogorov smirnov> 0,05 ( $a=5 \%)$, maka residual model regresi berdistribusi normal. Berikut adalah hasil uji kolmogorov smirnov residual:

Tabel 1.

Hasil Uji Normalitas

\begin{tabular}{|c|c|c|c|}
\hline & $\begin{array}{c}\text { Kolmogorov } \\
\text { Smirnov } \mathbf{Z}\end{array}$ & Signifikansi & Keterangan \\
\hline Unstandardized & 0,508 & 0,958 & normal \\
\hline
\end{tabular}

Sumber: Data Diolah

Berdasarkan Tabel diatas diketahui bahwa uji kolmogorov smirnov residual menghasilkan nilai signifikansi sebesar 0,958> 0,05, maka dapat disimpulkan residual model regresi berdistribusi normal, dan dengan demikian asumsi normalitas residual telah terpenuhi.

\section{Multikolinieritas}

Multikolinieritas menunjukkan adanya korelasi (hubungan) yang kuat antara 
Hidayat, et al/Jurnal Ekonomi Syariah Teori dan Terapan Vol. 4 No. 3 Maret 2017: 187-202; PENGARUH NON PERFORMING FINANCING, FINANCING TO DEPOSIT RATIO DAN INFLASI TERHADAP EFISIENSIMENGGUNAKAN RASIO BOPO PADA BANK SYARIAH DI INDONESIA PERIODE 2010-2015

variabel bebas dalam model regresi. Pendeteksian ada tidaknya multikolinieritas dilihat nilai tolerance dan nilai variance inflation factor (VIF). Apabila nilai VIF < 10 dan tolerance> 0,1 Berikut adalah nilai VIF yang dihasilkan model regresi:

Tabel 2.

Hasil Uji Multikolinieritas

\begin{tabular}{|c|c|c|c|}
\hline Variabel & Tolerance & VIF & Keterangan \\
\hline Inflasi & 0,872 & 1,147 & $\begin{array}{c}\text { Tidak Ada } \\
\text { Multkolinieritas }\end{array}$ \\
\hline NPF & 0,868 & 1,152 & $\begin{array}{c}\text { Tidak Ada } \\
\text { Multkolinieritas }\end{array}$ \\
\hline FDR & 0,781 & 1,281 & $\begin{array}{c}\text { Tidak Ada } \\
\text { Multkolinieritas }\end{array}$ \\
\hline
\end{tabular}

Sumber: Data Diolah

Berdasarkan Tabel diatas diketahui bahwa nilai VIF pada masing-masing variabel bebas semuanya kurang dari 10 dan tolerances 0,1 , sehingga dapat disimpulkan model regresi bebas dari multikolinieritas dengan demikian asumsi non multikolinieritas telah terpenuhi.

\section{Heteroskedastisitas}

Uji heteroskedastisitas bertujuan untuk menguji apakah dalam model regresi terjadi ketidaksamaan variance dari residual satu pengamatan ke pengamatan lain. Berikut ini disajikan grafik scatter plot untuk mengetahui heteroskedastisitas model regresi:

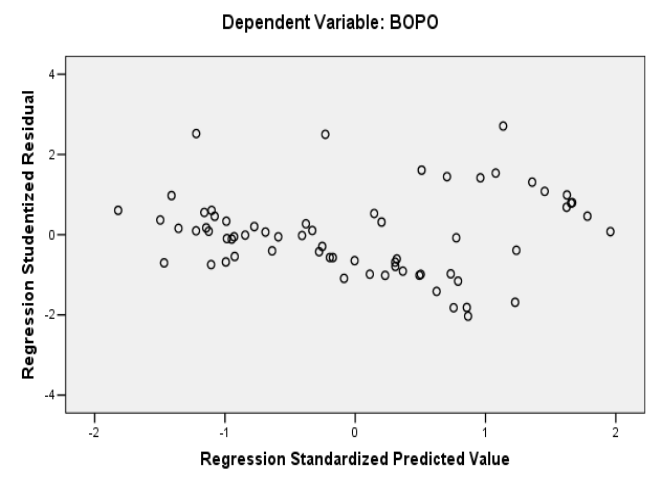

Gambar3. Scatter Plot

Sumber: Data Diolah

Berdasarkan grafik di atas dapat diketahui bahwa titik-titik pada grafik menyebar di atas dan di bawah nol pada sumbu $y$, sehingga dapat disimpulkan tidak terjadi heteroskedastisitas pada model regresi. Untuk memperkuat bahwa tidak terjadi heteroskedastisitas dilakukan uji rank spearmandengan cara mengkorelasikan antara variabel independen dengan nilai residualnya. Jika nilai signifikansi antara variabel independen dengan residual lebih dari 0,05 maka tidak terjadi masalah heteroskedastisitas. Berikut ini adalah hasil uji rank spearman:

Tabel 3.

Hasil Uji Heteroskedastisitas

\begin{tabular}{|c|c|c|}
\hline Variabel Bebas & Sig & Keterangan \\
\hline Inflasi & 0,855 & non Heteroskedastisitas \\
\hline NPF & 0,755 & non Heteroskedastisitas \\
\hline FDR & 0,946 & non Heteroskedastisitas \\
\hline
\end{tabular}

Sumber: Data Diolah

Berdasarkan Tabel diatas dapat dilihat bahwa nilai signifikansi dari uji rankspearman pada masing-masing variabel bebas lebih dari 0,05 , sehingga disimpulkan bahwa tidak terjadi heteroskedastisitas dalam model regresi, dengan demikian asumsi non heteroskedastisitas telah terpenuhi.

\section{Autokorelasi}

Autokorelasi menunjukkan dalam sebuah model regresi linier terdapat kesalahan pengganggu pada periode waktu dengan kesalahan pada periode waktu sebelumnya. Model regresi yang 
Hidayat, et al/Jurnal Ekonomi Syariah Teori dan Terapan Vol. 4 No. 3 Maret 2017: 187-202; PENGARUH NON PERFORMING FINANCING, FINANCING TO DEPOSIT RATIO DAN INFLASI TERHADAP EFISIENSIMENGGUNAKAN RASIO BOPO PADA BANK SYARIAH DI INDONESIA PERIODE 2010-2015

baik bebas dari autokorelasi.Pendeteksian ada tidaknya autokorelasi dapat dilakukan dengan menggunakan uji durbin watson (DW-test). Suatu observasi dikatakan tidak terjadi autokorelasi jika nilai DurbinWatson $\mathrm{dU}<\mathrm{dw}<4-\mathrm{dU}$.Berikut adalah nilai durbin Watsonyang dihasilkan dari model regresi:

Tabel 4. Hasil Nilai Durbin Watson

\begin{tabular}{|c|c|c|c|}
\hline $\begin{array}{c}\text { Durbin } \\
\text { Watson }\end{array}$ & $\mathbf{d U}$ & $\mathbf{4}-\mathbf{d U}$ & Keterangan \\
\hline 2,18 & 1,70 & 2,30 & non autokorelasi \\
\hline \multicolumn{2}{|c|}{ Sumber: Data Diolah }
\end{tabular}

Berdasarkan tabel 4.15 diketahui nilai durbin watson(DW) adalah 2,18, dimana nilainya berada diantara dU yaitu sebesar1,70dan 4 - dU sebesar2,30. Sehingga dari hasil tersebut mengindikasikan tidak terjadi autokorelasi pada model regresi, atau asumsi bebas autokorelasi pada model regresi terpenuhi.

\section{B. Uji Kriteria Statistik Model}

\section{Koefisien Determinasi $\left(R^{2}\right)$ dan} Adjusted $\mathbf{R}^{2}$

Pengujian pengaruh inflasi, NPF dan FDR terhadap BOPO menghasilkan nilai $R$ (korelasi berganda) dan nilai $R$ Square (koefisien determinasi berganda) sebagai berikut:

Tabel 5.

Nilai R dan R Square

\begin{tabular}{|c|c|c|}
\hline $\mathbf{R}$ & $\mathbf{R}$ Square & $\begin{array}{c}\text { Adjusted } \\
\mathbf{R} \text { Square }\end{array}$ \\
\hline 0,736 & 0,541 & 0,519 \\
\hline
\end{tabular}

Sumber: Data Diolah

Berdasarkan Tabel 4.16 diatas diketahui bahwa nilai $R$ yang diperoleh sebesar 0,736 menunjukkan bahwa hubungan inflasi, NPF dan FDR terhadap BOPO tergolong cukup kuat.

\section{Analisis Regresi Linear Berganda}

Dari hasil analisis regresi diperoleh persamaan regresi sebagai berikut:

\section{$\mathrm{BOPO}=60,984+0,718$ Inflasi $+6,109 \mathrm{NPF}-$ 0,057 FDR}

Penjelasan dari persamaan regresi di atas adalah:

1) $a=$ konstanta $=60,984$

Artinya jika variabel bebas Inflasi, NPF dan $F D R=0$, dengan kata lain jika Inflasi, NPF dan FDR tidak memberikan pengaruh maka BOPO adalah sebesar 60,984 .

2) $b_{1}=$ koefisien regresi Inflasi $=0,718$ Artinya jika inflasiberubah satu satuan, maka BOPO akan berubah sebesar 0,718 dengan anggapan variabel NPF dan FDR tetap. Tanda positif pada nilai koefisien regresi melambangkan hubungan yang searah antara NPF dan FDR, artinya apabila inflasisemakin tinggi, maka BOPO cenderung akan mengalami kenaikan sebesar 0,718.

3) $b_{2}=$ koefisien regresi NPF $=6,109$ Artinya jika NPFberubah satu satuan, maka BOPO akan berubah sebesar 6,109 dengan anggapan variabel inflasi dan FDR tetap. Tanda positif pada nilai koefisien regresi melambangkan hubungan yang searah antara NPF dan BOPO, artinya apabila NPF semakin tinggi, maka BOPO cenderung akan mengalami peningkatan sebesar 6,109.

4) $b_{3}=$ koefisien regresi $F D R=-0,057$ Artinya jika FDRberubah satu satuan, maka BOPO akan berubah sebesar 0,057 dengan anggapan variabel 
Hidayat, et al/Jurnal Ekonomi Syariah Teori dan Terapan Vol. 4 No. 3 Maret 2017: 187-202; PENGARUH NON PERFORMING FINANCING, FINANCING TO DEPOSIT RATIO DAN INFLASI TERHADAP EFISIENSIMENGGUNAKAN RASIO BOPO PADA BANK SYARIAH DI INDONESIA PERIODE 2010-2015

inflasi dan NPF tetap. Tanda negatif pada nilai koefisien regresi melambangkan hubungan yang berlawanan antara FDR dan BOPO, artinya apabila FDR semakin tinggi, maka BOPO cenderung akan mengalami penurunan sebesar 0,057.

\section{Uji †}

Berikut ini adalah hasil uji $\dagger$ untuk mengetahui pengaruh variabel bebas terhadap variabel terikat secara parsial.

Tabel 6.

Rangkuman Hasil Uji Hipotesis (Uji †)

\begin{tabular}{|c|c|c|c|c|c|}
\hline $\begin{array}{c}\text { Variabel } \\
\text { Bebas }\end{array}$ & B & $\begin{array}{c}\mathbf{t} \\
\text { hitung }\end{array}$ & Beta & Sig, & Ket \\
\hline Inflasi & 0,718 & 1,707 & 0,157 & 0,093 & $\begin{array}{c}\text { Tidak } \\
\text { signifikan }\end{array}$ \\
\hline NPF & 6,109 & 7,598 & 0,702 & 0,000 & signifikan \\
\hline FDR & $\begin{array}{c}- \\
0,057\end{array}$ & $-0,368$ & $\begin{array}{c}- \\
0,036\end{array}$ & 0,714 & $\begin{array}{c}\text { Tidak } \\
\text { signifikan }\end{array}$ \\
\hline
\end{tabular}

Sumber: Data Diolah

1. Inflasi secara parsial tidak berpengaruh signifikan terhadap BOPO.

2. NPF secara parsial berpengaruh signifikan terhadap BOPO.

3. FDR secara parsial tidak berpengaruh signifikan terhadap BOPO.

\section{Uji F}

Berikut ini adalah tabel hasil uji $F$ untuk menjawab hipotesis keempat.

Tabel 7.

Hasil Uji $F$

\begin{tabular}{|c|c|c|c|c|c|}
\hline Model & $\begin{array}{c}\text { Sum of } \\
\text { Squares }\end{array}$ & df & $\begin{array}{c}\text { Mean } \\
\text { Square }\end{array}$ & F hitung & Sig. \\
\hline Regression & 1708,277 & 3 & 569,426 & 24,357 & \\
\cline { 1 - 4 } Residual & 1449,426 & 62 & 23,378 & & \multirow{2}{*}{0,000} \\
\hline Total & 3157,703 & 65 & & & \\
\hline
\end{tabular}

Sumber: Data Diolah hasil uji $\mathrm{F}$ diperoleh nilai $\mathrm{F}$ hitung $=$ $24,357>\mathrm{F}$ tabel2,753 (dfl=3, df2=62, $a=0,05$ ) dan nilai signifikansi $=0,000<0,05$, maka disimpulkan bahwa inflasi, NPF dan FDR secara simultan berpengaruh signifikan terhadap BOPO. Hal ini berarti adanya peningkatan inflasi, NPF dan FDR secara bersama-sama akan meningkatkan BOPO.

\section{C.Pembahasan}

\section{Pengaruh NPF terhadap BOPO}

Bank syariah dalam melaksanakan perannya selalu dihadapkan dengan risiko, risiko terbesar pada bank syariah adalah kegiatan pembiayaan.Hal tersebut karena ekonomi syariah tidak mengenal adanya bebas risiko seperti yang dijelaskan sebagai berikut :

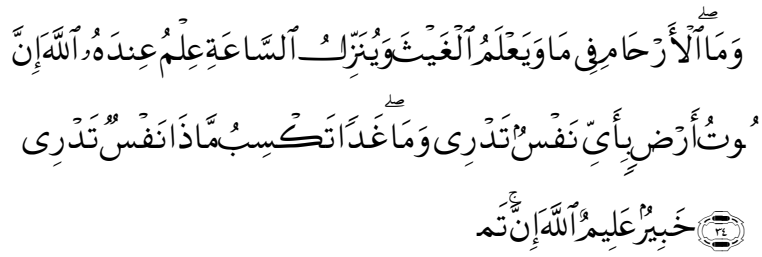

Innallāha 'indahū 'ilmus sā'ah(ti), wa yunazzilul gaiš(a), wa ya'lamu mā fil arhām(i), wa mā tadrīnafsum māżā taksibu gadā(n), wa mā tadrī nafsum biayyi arḍin tamūt(U), innallāha 'alimun khabìr(un). Artinya : "...Dan tiada seorangpun yang dapat mengetahui (dengan pasti) apa yang akan diusahakannya besok. dan tiada seorangpun yang dapat mengetahui di bumi mana Dia akan mati. Sesungguhnya Allah Maha mengetahui lagi Maha Mengenal"

(QS. Luqman/31:34, kementrian Agama Republik Indonesia 2006: 414)

Ayat tersebut menjelaskan tentang ketidaktahuan umat manusia terhadap apa yang akan terjadi dimasa depan. Banyaknya pembiayaan yang bermasalah di bank menimbulkan tingginya rasio NPF di bank tersebut. Jika terjadi pembiayaan bermasalah dan nasabah tidak dapat 
Hidayat, et al/Jurnal Ekonomi Syariah Teori dan Terapan Vol. 4 No. 3 Maret 2017: 187-202; PENGARUH NON PERFORMING FINANCING, FINANCING TO DEPOSIT RATIO DAN INFLASI TERHADAP EFISIENSIMENGGUNAKAN RASIO BOPO PADA BANK SYARIAH DI INDONESIA PERIODE 2010-2015

membayar angsuran pembiayaan yang diambilnya maka dapat menimbulkan biaya operasional berupa biaya penagihan kepada nasabah tersebut.

Rasio NPF Perbankan Syariah di Indonesia pada pertengahan2015 mengalami kenaikan hingga batas maksimum yang di tetapkan Bank Indonesia $5 \%$ yaitu sebesar $4,73 \%$ yang $57 \%$ nya brasal dari pembiayaan non UKM. Naiknya rasio NPF bank syariah dikarenakan Cost of Fund di bank syariah cenderung tinggi. Pada tahun 2015 bukan hanya rasio NPF yang tinggi namun rasio BOPO juga ikut naik hingga sebesar $86,87 \%$.

Sejak tahun 2012 rasio BOPO di perbankan syariah memang sudah tinggi karena Bank syariah masih belum berkembang seperti saat ini. Menurut Dinno Indiano Direktur Utama BNI Syariah, "Kenaikan BOPO ini juga disebabkan oleh pencadagan yang terbentuk akibat pembiayaan bermasalah (NPF), beberapa bank syariah membuat cadangan yang lebih karena ditengah kondisi ekonomi seperti sekarang ini NPF pasti meningkat". Untuk menurunkan rasio BOPO pemerintah dapat melakukan menghilangkan cost of Fund atau dana mahal, yaitu dengan cara dana APBN agar disimpan di bank syariah sehingga bisa meningkatkan DPK bank syariah.

Berdasarkan hasil penelitian ini diketahui bahwa Non Performing Financing (NPF)berpengaruh signifikan terhadapBOPO. Hal tersebut ditunjukkan oleh nilai signifikansi NPF dibawah 0,05 yaitu sebesar 0,000 sehingga $\mathrm{H}_{0}$ ditolak. Selain itu, dari hasil regresi anilisis data penelitian ini sebesar 6,109menunjukkan NPF memiliki hubungan yang positif terhadap BOPO.

\section{Pengaruh FDR terhadap BOPO}

Berdasarkan hasil penelitian ini diketahui bahwa Financing to Deposit Ratio (FDR)tidak berpengaruh signifikan terhadapBOPO.Dengan signifikansi FDR sebesar 0,714 dimana nilai signifikansinya lebih besar dari 0,05sehingga $\mathrm{H}_{0}$ diterima. Selain itu, dari hasil regresi anilisis data penelitian ini sebesar -0,057 menunjukkan FDR memiliki hubungan negatif terhadap BOPO.

FDR pada perbankan syariah tinggi karena banyakya dana yang di miliki bank disalurkan ke pembiayaan. Hal tersebut karena minimnya instrumen likuiditas bank syariah, di indonesia instrumen likuiditas bank syariah hanya tiga yaitu SBI Syariah, FASBI Syariah dan REPO Syariah saja.Sedikitnya instrumen likuiditas pada bank syariah dan minimnya perusahaan yang berbasis syariah, sehigga tidak banyak perusahaannya yang dapat diberikan investasi oleh bank syariah.

FDR tertinggi selama periode penelitian ini pada tahun 2012 hingga 2013, yaitu pada 2012 hingga 2013 yaitu sebesar 96,82\% pada 2012 dan 102,63\% pada 2013. Namun pada tahun 2012 hingga 2013 rasio BOPO berada pada posisi terendah selama periode peelitian. Hal tersebut sesuai dengan hasil penelitian ini, bahwa FDR dan BOPO memiliki hubungan yang negatif sehingga jika rasio FDR naik maka rasio BOPO akan turun. 
Hidayat, et al/Jurnal Ekonomi Syariah Teori dan Terapan Vol. 4 No. 3 Maret 2017: 187-202; PENGARUH NON PERFORMING FINANCING, FINANCING TO DEPOSIT RATIO DAN INFLASI TERHADAP EFISIENSIMENGGUNAKAN RASIO BOPO PADA BANK SYARIAH DI INDONESIA PERIODE 2010-2015

\section{Pengaruh Inflasi terhadap BOPO}

Pada periode tahun penelitian yaitu 2010 hingga 2015 inflasi di Indonesia terbilang cukup buruk, terutama pada tahun 2013 hingga 2014 yang mencapai 8,38\%. Pada tahun tersebut tingginya inflasi disebabkan oleh naiknya harga bahan makanan di Indonesia. Penyebab tingginya inflasi di Indoesia kebanyakan karena naiknya harga BBM dan dampakya terhadap harga bahan makanan yang ikut meningkat. Seperti pada tahun 2013 hingga 2014 adanya kenaikan BBM menyebabkan harga barang-barang naik.

Pertumbuhan inflasi tidak seberapa berpengaruh terhadap BOPO pada bank syariah, hal tersebut dapat dilihat pada tingginya inflasi pada 2010 dan 2013 hingga 2014, rasio BOPO di perbankan syariah tidak mengalami kenaikan yang terlalu besar. Pada tingkat inflasi terbesar selama periode penelitian yaitu tahun 2013 hingga 2014 tingkat rasio BOPO malah berada pada posisi terendah selama periode penelitian. Hal tersebut sesuai dengan hasil pada penelitian ini bahwa tingkat inflasi berpengaruh positif terhadap rasio BOPO namun tidak berpengaruh secara signifikan.

Berdasarkan hasil penelitian ini diketahui bahwa Inflasitidak berpengaruh signifikan terhadap BOPO, dengan signifikansi Inflasi sebesar 0,093. Selain itu, dari hasil regresi anilisis data penelitian ini sebesar 0,178menunjukkan inflasi memiliki hubungan positif terhadap BOPO.

\section{Pengaruh Secara Simultan terhadap BOPO}

Berdasarkan hasil penelitian ini diketahui bahwa NPF, FDR dan Inflasiberpengaruh secara simultan terhadap BOPO, meskipun secara parsial dua variabel diantara ketiga variabel tidak berpengaruh signifikansi terhadap BOPO. Berdasarkan hasil uji $F$ diperoleh nilai signifikansi $=0,000<0,05$, maka disimpulkan bahwa inflasi, NPF dan FDR secara simultan berpengaruh signifikan terhadap BOPO dan $\mathrm{H}_{0}$ ditolak. Hal ini berarti adanya peningkatan inflasi, NPF dan FDR secara bersama-sama akan meningkatkan BOPO.

\section{Pengaruh NPF Secara Dominan terhadap BOPO}

Berdasarkan hasil penelitian ini diketahui bahwa Non Performing Financing (NPF)berpengaruh dominan terhadap BOPO. Hal tersebut ditunjukkan oleh nilai signifikansi NPF dibawah 0,05 yaitu sebesar 0,000dan paling kecil dari nilai signifikansi variabel yang lain.Variabel NPF merupakan satu-satunya variabel yang berpengaruh signifikan terhadap BOPO, sehingga dapat dipastikan jika NPF merupakan variabel yang paling berpengaruh dominan terhadap BOPO. Variabel yang berpengaruh dominan dapat dilihat dari nilai koefisien regresi yang paling tinggi.

\section{SIMPULAN}

1. Non Performing Financingsecara parsial memiliki pengaruh yang signifikan terhadap Biaya Operasional terhadap Pendapatan Operasional BUS dan UUS dengannilai signifikasi 
Hidayat, et al/Jurnal Ekonomi Syariah Teori dan Terapan Vol. 4 No. 3 Maret 2017: 187-202; PENGARUH NON PERFORMING FINANCING, FINANCING TO DEPOSIT RATIO DAN INFLASI TERHADAP EFISIENSIMENGGUNAKAN RASIO BOPO PADA BANK SYARIAH DI INDONESIA PERIODE 2010-2015

0,000 dan memiliki pengaruh positif yang ditunjukkan olehkoefisien regresisebesar 7,598. Hasil tersebut dapat disimpulkan bank harus menjaga tingkat rasio NPF tetap dibawah 5\% agar rasio BOPO tidak akan ikut naik juga.

2. Financing to Deposit Ratio memiliki pengaruh yang tidak signifikan terhadap Biaya Operasional terhadap Pendapatan Operasional BUS dan UUS dengan nilai signifikasisebesar 0,714 dan memiliki pengaruh negatif yang ditunjukkan oleh koefisien regresisebesar -0,368. Hasil tersebut dapat disimpulkan bahwa banyaknya pembiayaan yang disalurkan akan meningkatkan pendapatan dari bagi hasil pembiayaan tersebut, sehingga tingginya rasio FDR sampai batas wajarnya akan berdampak baikuntuk karena rasio BOPO akan menurun.

3. Inflasi secara parsial memiliki pengaruh yang tidak signifikan terhadap Biaya Operasional terhadap Pendapatan Operasional BUS dan UUS dengan nilai signifikasi sebesar 0,093 namun memiliki pengaruh positif yang ditunjukkan oleh koefisien regresi sebesar 1,707. Hasil tersebut dapat disimpulkan jika Inflasi tidak terlalu berpengaruh pada profitabilitas bank dengan tolak ukur rasio BOPO.

4. Non Performing Financing, Financing to Deposit Ratio dan Inflasi secara simultan memiliki pengaruh terhadap
Biaya Operasional terhadap Pendapatan Operasional BUS dan UUS dengan persamaan regresi berganda:

$$
\begin{gathered}
\mathrm{BOPO}=60,984+(0,718) \text { Inflasi }+ \\
6,109(\mathrm{NPF})-0,057(\mathrm{FDR})
\end{gathered}
$$

Berdasarkan kesimpulan tersebut, maka disarankan bagi penelitian selanjutnya untuk memasukkan variabelvariabel lain diluar variabel ini, agar memperoleh hasil yang lebih bervariatif yang dapat menggambarkan hal-hal yang dapat berpengaruh terhadap Biaya Operasional terhadap Pendapatan Operasional (BOPO) dan dapat memperpanjang periode pengamatan.

\section{DAFTAR PUSTAKA}

Al-Quran dan Terjemahannya. (2006). Departemen Agama Rl. Jakarta: Magfirah Pustaka.

Andi Arifin. (2009). Analisis Tingkat Efisiensi Bank dengan pendekatan Data Envelopment Analisis (DEA). Semarang: Universitas Brawijaya.

Anshori, Muslich \& Sri Iswati. (2009). Buku Ajar Metodologi Penelitian Kuantitatif. Cetakan pertama. Surabaya: Airlangga University Press.

Ascarya. (2007). Akad dan Produk Bank Syariah. Jakarta: Rajawali Pres.

Boediono Dr., 1985. Ekonomi Makro. Seri Sinopsis Pengantar IImu Ekonomi No. 2 Edisi 4. Yogyakarta: BPFE-YOGYAKARTA.

Dahlan, Siamat (2001). Manajemen Lembaga Kevangan. Jakarta: Lembaga Peneliti Fakultas Ekonomi Universitas Indonesia.

Dendawijaya, Lukman. (2009). Manajemen Perbankan. Jakarta: Ghalia Indonesia. 
Dewi, Gemala. (2007). Aspek-aspek Hukum Dalam Perbankan dan Peransuransian Syariah di Idonesia. Jakarta: Kencana.

Fauziah, Ravika. (2012) dalam skripsinya yang berjudul "pengaruh inflasi terhadap tingkat profitabilitas Bank Muamalat dan Bank Central Asia tahun 2007-2011". Skripsi tidak dipublikasikan. Surabaya: Universitas Negeri Surabaya.

Ghozali, Imam. (2001). Aplikasi Analisis dengan Program SPSS. Semarang. Badan Penerbit Universitas Diponegoro

Ghozali, Imam. (2013). Aplikasi Analisis Multivariate dengan Program IBM SPSS 21 Update PLS Regresi. Semarang: Badan Penerbit Universitas Diponegoro.

Hartono. 2007. Pengaruh Dana Pihak Ketiga dan Suku Bunga Sertifikat Bank Indonesia Terhadap Non Performing Financing Pada Bank Muamalat Indonesia. Jakarta: Tesis S-2 Ekonomi dan Keuangan Syariah Program Studi Timur Tengah dan Islam Program Pascasarjana Universitas Indonesia.

Karim, Ir. Adiwarman A. (2007). Ekonomi Makro Islami. Edisi Kedua. Jakarta: PT Rajagrafindo Persada.

Mankiw, N. Gregory, et al. (2013). Pengantar Ekonomi Makro, Principles Of Economics An Asian Edition-Volume 2. Jakarta: Penerbit Salemba Empat.

Martono dan Agus Harjito. (2008). Manajemen Kevangan. Yogyakarta : EKONISIA.

Muhammad. (2005). Bank Syariah. Graha IImu, Yogyakarta.

Muhammad. (2004). Manajemen Dana Bank Syari'ah. Edisi Pertama. Yogyakarta: Ekonisia. Kampus Fakultas Ekonomi UII.

Peraturan Bank Indonesia, Bank Indonesia.

Setyawati, A.A Putu dan I Wayan Suartana. (2014). "Pengaruh Pertumbuhan Aktiva Produktif, Dana Pihak Ketiga, Tingkat Kredit Bermasalah dan Ukuran LPD pada
Kinerja Operasional". Tesis Universitas Udayana, tidak dipublikaskan,

Riyadi Slamet, 2006. Banking Assets and Liability Management (Edisi Ketiga). Jakarta: Lembaga Penerbit Fakultas Ekonomi Universitas Indonesia, 2006.

Santoso, Harry. (2011). "Pengaruh Non Performing Loan terhadap Rasio BOPO (Studi kasus pada Bank yang Listing di Bursa Efek Indonesia)". Tesis Universitas Widyatama, tidak dipublikasikan.

Statistik Perbankan Indonesia, Bank Indonesia.

Statistik Perbankan Syariah, Bank Indonesia.

Sudarsono, Heri, 2003. Bank dan Lembaga Keuangan Syariah Deskriptif dan Ilustrasi, Yogyakarta: Penerbit Ekonisia Kampus Fakultas Ekonomi UI.201201

Sudarsono, Heri, 2004. Bank dan Lembaga Kevangan Syariah. Yogyakarta: Ekonisia

Sugiyono. (2009). Memahami Penelitian Kuantitatif. Sugiyono. (2011). Statistika untuk Penelitian. Bandung: Alfabeta.

Sukirno, Sadono. 2006. Makroekonomi Teori Pengantar. Edisi Ketiga. Jakarta: Rajawali Pers.

Syafi'i Antonio, Muhammad. (2001). Bank Syariah: Dari Teori ke Praktek. Jakarta: Gema Insani Press.

Tri Septiani, Dwi. (2012). "Analisis Efisiensi Kinerja Operasional Bank dengan Menggunakan Rasio Biaya Operasional Terhadap Pendapatan Operasional (BOPO) Pada Bank Mandiri Syariah KCP Braga Bandung". Tesis Universitas Komputer Indonesia, tidak dipublikasikan.

Widarjono, Agus. (2010). Analisis Statistika Multivariat Terapan. Yogyakarta: Unit Penerbit dan Percetakan.

http://www.bi.go.id/id/moneter/inflasi/pen genalan/Contents/Default.aspx.

(Diakses pada 7 november 2015 19.47)

http://www.alquran-indonesia.com/web/. (Diakses pada 7 november 2015 21.04)

http://m.republika.co.id/berita/ekonomi/sy ariah-ekonomi/15/05/26/noy4bv-bisnisperbankan-syariah-yang-terbatas-buat- 
Hidayat, et al/Jurnal Ekonomi Syariah Teori dan Terapan Vol. 4 No. 3 Maret 2017: 187-202; PENGARUH NON PERFORMING FINANCING, FINANCING TO DEPOSIT RATIO DAN INFLASI TERHADAP EFISIENSIMENGGUNAKAN RASIO BOPO PADA BANK SYARIAH DI INDONESIA PERIODE 2010-2015

fdr-tinggi . (Diakses pada 20 mei 2016 20.01)

http://m.kontan.co.id/news/rasio-boponaik-bank-syariah-tingkatkan-efisiensi. (Diakses pada 20 mei 2016 19.47) http://m.detik.com/finance/read/2014/01/0 2/140940/2456664/4/ini-penyebabmeroketnya-inflasi-2013-dari-bbmhingga-rokok-kretek. (Diakses pada 20 mei 2016 20.24) 